CONTI, J.H.; MINAMI, K.; TAVARES, F.C.A. Produção e qualidade de frutos de morango em ensaios conduzidos em Atibaia e Piracicaba. Horticultura Brasileira, Brasília, v. 20,n.1, p. 10-17, março 2.002.

\title{
Produção e qualidade de frutos de diferentes cultivares de morangueiro em ensaios conduzidos em Atibaia e Piracicaba.
}

\author{
José Henrique Conti; Keigo Minami; Flavio C. A. Tavares \\ ESALQ, C. Postal 83, 13.418-900 Piracicaba-SP; E-mail: jhconti@hiway.com.br
}

\section{RESUMO}

Foram instalados experimentos em Atibaia (SP), região de clima ameno, e Piracicaba (SP), região de clima quente, no ano de 1996, com delineamento em blocos ao acaso, com quatro repetições e dezesseis plantas por parcela, com as cultivares Campinas, Dover, Guarani, Princesa Isabel e AGF 080. Dos frutos avaliou-se a presença de "pescoço", formato, teor de sólidos solúveis, $\mathrm{pH}$, cor interna e externa, textura e a produção e seus componentes. Atibaia destacou-se pela produção maior de frutos $(468,30 \mathrm{~g} /$ planta $)$, maior número de frutos (46,75 frutos/planta) e maior peso médio de fruto $(10,06 \mathrm{~g})$ em relação a Piracicaba. As características do fruto e da planta do morangueiro foram pouco variáveis ao efeito de locais. As medidas de cor interna, textura e presença de pescoço possibilitaram indicar a cultivar Guarani como apto para o uso industrial e Dover como pouco indicado. Em função das medidas de peso, teor de sólidos solúveis, pH e textura, as cultivares Campinas, AGF 080 e Princesa Isabel são as mais adequadas ao consumo "in natura", enquanto que Guarani e Dover são pouco adequadas. Os dados de resistência à compressão, que estimam a textura dos frutos, comprovam que as cultivares Guarani, Dover e Princesa Isabel são as mais resistentes ao transporte e Campinas e AGF 080 as menos resistentes.

Palavras-chave: Fragaria x ananassa Duch., cultivares, clima, tropical, consumo 'in natura', rendimento.

\begin{abstract}
Production and quality of some cultivars of strawberry fruits in field experiments at Atibaia and Piracicaba, Brazil.

Field experiments were carried out in São Paulo State (Brazil), in Atibaia, Cfb climate and Piracicaba, Cwa climate, in 1996. The experimental design was of randomized blocks with four replications and sixteeen plants per plot using the cultivars Campinas, Dover, Guarani, Princesa Isabel and AGF 080. The presence of neck, shape, yield, number and average weight, amount of soluble solids, $\mathrm{pH}$, external and internal color, texture and components of yield and of the fruits were evaluated. Atibaia experiment resulted in greater production of fruits (468,30 g/plant), greater number of fruits $(46,75$ fruits/plant) and greater fruit mean weight $(10,06 \mathrm{~g})$ in relation to Piracicaba. Characteristics of the strawberry fruit and plant were not influenced by local effects. The internal color measures, texture and neck presence indicate the cv. Guarani suitable for industrial purposes. In function of the weight measures, amount of soluble solids, $\mathrm{pH}$ and texture, the Campinas, Agf 80 and Princesa Isabel cvs. are the most suitable for the fresh market while Guarani and Dover are inadequate. Guarani, Dover and Princesa Isabel are the most resistant cvs. to transportation and Campinas and Agf 80 are the less resistant.
\end{abstract}

Keywords: Fragaria $x$ ananassa Duch., climate, tropical, fresh market, yield.

(Aceito para publicação em 14 de fevereiro de 2.002)

U ma complexa interação entre os fatores temperatura e comprimento do dia determinam o desempenho produtivo e a qualidade dos frutos em cultivares de morangueiro em uma determinada região produtora $(\mathrm{Scott} \&$ Lawrence, 1975). Em vista disso, quando uma cultivar é selecionada para determinada região fisiográfica e plantada em outra, dificilmente apresentará elevada produção de frutos de qualidade (Dávalos, 1979). Human \& Evans (1989) e Rice Jr. (1990) testaram cultivares do morangueiro na África e confirmaram que estas, quando melhoradas para regiões temperadas, não mostraram bom desempenho em áreas tropicais.

As principais regiões brasileiras produtoras de morango localizam-se em áreas de clima tropical de altitude elevada, ameno. Atualmente a cultura está se expandindo para áreas de clima tropical de altitude média, quente. A produção comercial do morango no Brasil está baseada em poucas cultivares. A 'Campinas', selecionada para consumo in natura na década de cinqüenta pelo IAC (Camargo, 1960), ainda hoje é uma das mais cultivadas. Na década de setenta foi lançada a cultivar Guarani para uso industrial e, na década de oitenta, a cultivar Princesa Isabel com frutos mais duráveis após a colheita (Passos \& Camargo, 1993). Na década de noventa foi importada dos EUA a cultivar Dover, selecionada, segundo Howard \& Albregts (1980), para a resistência a antracnose nas condições da Florida.
A alta incidência de antracnose, doença conhecida como "flor preta" no morangueiro, tem levado os agricultores a buscar novas alternativas de produção. Entre elas, a utilização de novas cultivares supostamente mais resistentes, como a 'Dover', estão sendo avaliadas. Por a introdução dela ser recente, não há dados científicos sobre o seu desempenho em nossas condições. Sabe-se que na região produtora de Atibaia e Jarinu (SP) a mesma tem apresentado suscetibilidade à bacteriose, resistência duvidosa à antracnose e características de frutos inadequadas ao consumo in natura. No entanto, teve grande aceitação pelos agricultores quando estes, para escapar da antracnose, mudaram o local de plantio para áreas no- 
vas distantes dos mercados consumidores e pela textura muito firme dos frutos, mostrou-se adequada para o transporte a longas distâncias. Também estão sendo avaliadas mudanças no sistema de produção. Com a finalidade de estudar a introdução da irrigação por gotejamento, o cultivo protegido e o uso de cobertura morta de solo orgânica ou de polietileno, Passos (1997) realizou trabalho na região produtora de Atibaia e Jarinu com a cultivar Campinas.

A introdução de germoplasma exótico, vem sendo realizada pelos próprios produtores sem que estes novos materiais sejam avaliados adequadamente quanto à adaptabilidade ao cultivo em condições tropicais e exigências do mercado consumidor. Estes frutos de morango sendo oferecidos no mercado com características de qualidade inadequadas, têm resultado em menor consumo da fruta e, como conseqüência, prejuízos ao agricultor. Assim foi proposto o presente trabalho, com o objetivo de avaliar o desempenho de diferentes cultivares de morangueiro quanto à produção e seus componentes e a qualidade dos frutos em Atibaia e em Piracicaba, regiões de clima ameno e quente respectivamente.

\section{MATERIAL E MÉTODOS}

Foram avaliadas neste trabalho as cultivares Campinas, Guarani e Princesa Isabel desenvolvidas pelo IAC (Passos \& Camargo, 1993), a cultivar AGF 080 pela empresa Agroflora e a cultivar Dover selecionada na Flórida (Howard \& Albregts, 1980), cultivadas em duas regiões distintas, Atibaia e Piracicaba.

Piracicaba está localizada na latitude de $22^{\circ} 43^{\prime}$, longitude de $47^{\circ} 37^{\prime}$ e a uma altitude de $505 \mathrm{~m}$, e Atibaia em latitude de $23^{\circ} 07^{\prime}$ e longitude de $46^{\circ} 33^{\prime}$ e o experimento estava a uma altitude de $811 \mathrm{~m}$. Em Piracicaba, o experimento foi plantado em solo denominado Terra Roxa Estruturada e clima do tipo Cwa segundo classificação pelo sistema internacional de Koeppen e em Atibaia, em Latossolo Vermelho Escuro e clima predominante $\mathrm{Cfb}$.

Os frutos foram coletados em experimentos em 1996, nos municípios de Atibaia e Piracicaba, respectivamente em campo de produção comercial de frutos e em área experimental do Departamento de Horticultura da ESALQ. Os experimentos obedeceram o mesmo delineamento experimental em blocos casualizados com quatro repetições de cinco cultivares e parcelas constituídas de dezesseis plantas, sem bordadura como proposto pôr Nagai et al. (1978). A cobertura de solo foi feita com filme plástico de polietileno preto e irrigação por aspersão. Em Atibaia foram plantadas mudas de raiz nua em 25 de março de 1996 e, após cinco floradas, as plantas foram retiradas no dia 7 de novembro. Em Piracicaba as mudas eram de torrão, e foram plantadas em 30 de abril de 1996 e retiradas no dia 28 de novembro, após cinco floradas.

As características do fruto analisadas nas diferentes cultivares foram a presença de "pescoço" (prolongamento afunilado na base do fruto); o formato; a produção e seus componentes; o teor de sólidos solúveis, o $\mathrm{pH}$, a textura e a coloração externa e interna. O "pescoço" foi estudado com base no trabalho de Passos et al. (1994), em cinqüenta frutos no estágio maduro, na segunda florada, por parcela.

Para a análise da forma dos frutos nas cultivares Campinas, Dover, Princesa Isabel e AGF 080, que apresentam frutos com formato cônico ou cônico alongado, foi desenvolvido um método que consiste em cortar os frutos de morango ao meio no sentido do maior comprimento. A face cortada de uma das metades do fruto foi pressionada em uma folha de cartolina branca onde deixou uma marca. Em torno da marca foi traçado um triângulo onde a mesma ficou inscrita. Foram analisados, por este método, cinqüenta frutos de segunda ou terceira ordem, no estágio maduro, na segunda florada por parcela. Em cada triângulo foram medidas a base e a altura; A razão entre as mesmas foi utilizada na obtenção das médias de cada cultivar.

O teor de sólidos solúveis e o $\mathrm{pH}$ foram obtidos (100 $\mathrm{g}$ de frutos, de terceira florada em cada parcela) triturando os frutos em liqüidificador juntamente com $100 \mathrm{ml}$ de água por três minutos a alta velocidade, seguindo o descrito por Passos (1982). No material obtido foram realizadas três medidas de $\mathrm{pH}$, com volume de $50 \mathrm{ml}$, (peagâmetro da marca Analion) e três medidas de quantidade de sólidos solúveis expressos em graus Brix (densitômetro marca Anton Paar, modelo DMA 46).

A textura foi obtida em texturômetro TA-XT2 nas seguintes condições: os frutos foram medidos individualmente nas mesmas condições, determinandose a força de resistência à compressão na condição de retorno ao início ("return to start"). A ponta de prova ("probe") utilizada foi a haste de base plana de 3 $\mathrm{mm}$ de diâmetro. Foram utilizadas as velocidades de perfuração de $2 \mathrm{~mm} / \mathrm{s}$ na fase pré-teste teste, $1 \mathrm{~mm} / \mathrm{s}$ na fase teste e $2 \mathrm{~mm} / \mathrm{s}$ na fase pós-teste. A distância de perfuração foi padronizada em 10 $\mathrm{mm}$ e o resultado expresso pela força máxima (g). Para cada análise tomaramse cinco frutos maduros ao acaso, de terceira florada por parcela.

A cor dos frutos de morango foi quantificada em espectrofotômetro COMCOR 1500 PLUS e os dados obtidos correspondem aos componentes analíticos $\mathrm{L}^{*}, \mathrm{a}^{*} \mathrm{e} \mathrm{b*}$, segundo o descrito por Ferreira (1981). Os valores de $\mathrm{L}^{*}$ variam do claro ao escuro, sendo o valor 100 correspondente à cor branca e o valor 0 (zero) à cor preta; o componente $a *$ varia entre o vermelho e o verde onde os valores positivos correspondem ao vermelho, o 0 (zero) ao cinza e os valores negativos, à cor verde; o componente $b^{*}$ varia do azul ao amarelo onde os valores negativos correspondem ao azul, o 0 (zero) ao cinza e os valores positivos, à cor amarela. Os valores de $a^{*}$ e $b^{*}$ foram convertidos ao índice $\mathrm{c}^{*}$ (croma), obtido da raiz quadrada de $a^{* 2}+b^{* 2}$. A cor do fruto inteiro foi determinada com a seguinte configuração do aparelho: abertura pequena, uv (ultra violeta) excluso, brilho incluso, ângulo de $10^{\circ}$, leitura média de quatro determinações em cada parcela. A cor do morango cortado foi determinada na mesma configuração, com a única diferença que a abertura utilizada foi a normal. Os frutos foram cortados longitudinalmente e as metades arranjadas no vidro óptico, contidas pelo anel de PVC. Foram colocadas três a quatro camadas de frutos, arranjadas de modo a não deixar espaços vazios, colocan- 
do-se na mesma camada metades de frutos diferentes. Também foram realizadas quatro determinações por parcela dos experimentos com frutos maduros de terceira ordem.

O estudo da coloração de frutos, através da análise dos componentes $\mathrm{L}^{*}$ (luminosidade) e de $\mathrm{a}^{*} \mathrm{e} \mathrm{b}^{*}$ que juntos resultam no valor de $\mathrm{c}^{*}$ (croma), é uma maneira de quantificar a característica cor. Em morangos, vários trabalhos com estes componentes da cor foram realizados tanto para a cor externa como interna dos frutos. Miszczak et al. (1995) e Paraskevopoulou-Paroussi et al. (1995) estudaram o comportamento dos componentes $\mathrm{L}^{*}, \mathrm{a}^{*} \mathrm{e} \mathrm{b}^{*}$ em morangos inteiros pós colheita e concluíram que os valores de $\mathrm{L}^{*}, \mathrm{a}^{*} \mathrm{e} \mathrm{b}^{*}$ diminuem conforme avança o tempo de armazenamento, ou seja, neste período os frutos amadurecem e tornam-se mais vermelho-escuros visualmente. Sacks \& Shaw (1993) estudaram a cor interna dos morangos e concluíram que em sete dias de armazenamento os frutos se tornaram mais escuros e mais cromáticos, isto é, apresentaram valores menores de L* e elevados de croma enquanto que, na coloração externa, quanto mais amadurecem os frutos, estes apresentam-se mais escuros e menos cromáticos. Baseados nestas constatações e considerando que as cultivares estudadas apresentam diferenças visuais de cor externas e internas desde o vermelho claro até o escuro, foi proposta, no presente trabalho, uma classificação para coloração em frutos de morango utilizando os valores de L* e c*. Estabeleceu-se uma faixa intermediária, baseando-se na média de todas as cultivares e considerando o desvio padrão para mais e para menos da média, como a amplitude daquelas cultivares que estão nesta faixa. Assim, considerando o componente L* como a luminosidade indicativa do grau de claro e escuro, é viável estabelecer que para a coloração externa, valores menores que 29,24 indicam cor escura, valores de $L^{*}$ entre 29,34 e 34,62 indicam condição intermediária e valores maiores que 34,62 cor clara. Para a coloração interna, valores menores que 38,35 indicam cor escura, valores entre 38,35 e 51,57 são intermediários e maiores que 51,57 de cor clara. $\mathrm{O}$ valor de

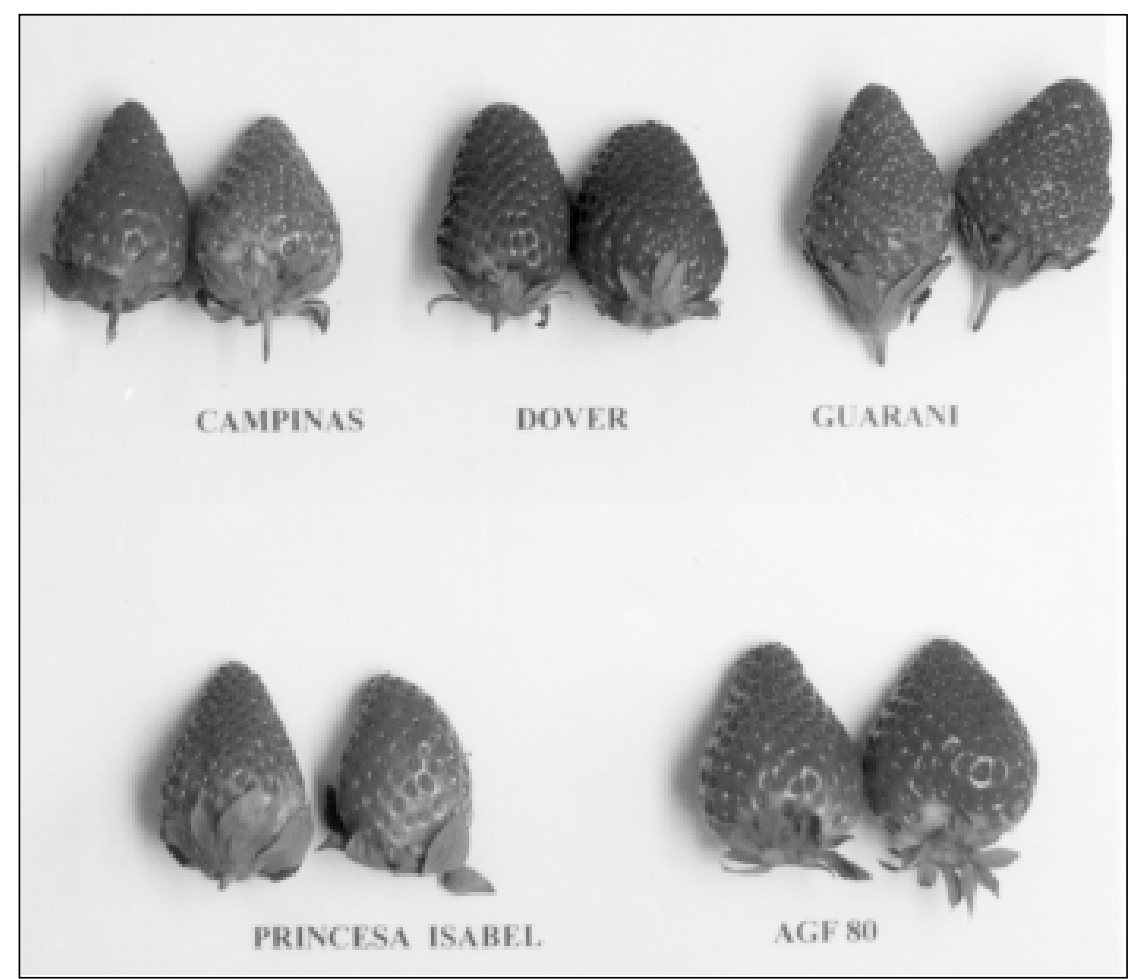

Figura 1. Frutos das cultivares: forma dos frutos, ocorrência de "pescoço" e cor externa. Piracicaba, ESALQ, 1996.

c* expressa o grau de croma dos frutos, onde, pela classificação proposta, frutos mais coloridos externamente apresentam valores menores que 24,92 , a faixa intermediária está entre este valor e 36,08 e os frutos menos coloridos têm valores de croma maiores que 36,08 . O valor de $\mathrm{c}^{*}$, na coloração interna dos frutos, apresentou uma faixa intermediária entre 33,28 e 42,88, assim frutos menos cromáticos apresentam valores de $c^{*}$ menores que 33,28 e os mais cromáticos valores maiores que 42,88.

A produção total de frutos, o número de frutos e o peso médio dos frutos foi obtida da colheita. Esta foi feita em todas as plantas de cada uma das parcelas, ocorreu quando os frutos estavam entre os estágios " $3 / 4$ maduros" e "maduros", duas vezes por semana, durante todo o período de produção sendo contados e pesados os frutos "comerciáveis", isto é, aqueles apropriados para o consumo (Passos, 1982; Passos, 1997; Tessarioli Neto, 1982; Tessarioli Neto, 1993).

Os resultados de formato, $\mathrm{pH}$, teor de sólidos solúveis, textura, cor interna e externa, produção, número e peso médio dos frutos foram submetidos à análise de variância e as diferenças entre as médias dos tratamentos foram comparadas por Tukey a $5 \%$ de probabilidade. A análise dos dados de presença de "pescoço" considerou a presença ou ausência de determinada estrutura se esta estiver presente em 95\% da amostra (Queiroz-Voltan et al., 1996).

Os resultados dos experimentos, embora obtidos separadamente, puderam ser analisados em conjunto, pois a relação entre os quadrados médios dos resíduos dos dois experimentos foi menor que sete para todas as características estudadas (Cruz \& Regazzi, 1994).

\section{RESULTADOS E DISCUSSÃO}

A característica presença de "pescoço" foi útil para caracterizar e também para ajudar na determinação da finalidade de uso de algumas cultivares. As cultivares Guarani e Dover foram caracterizadas pela ausência ou presença desta característica, sendo ausência de "pescoço" em 'Dover' (100,0\% dos frutos analisados) e presença de "pescoço" em 'Guarani' (97,7\% dos frutos analisados). Campinas apresentou $67,2 \%$ dos frutos com "pescoço", AGF 080 79,0\% dos 
Tabela 1. Razão entre a base e a altura do triângulo circunscrito, teor de sólidos solúveis (graus Brix), pH, textura, cor interna e externa pelos componentes luminosidade $\left(\mathrm{L}^{*}\right)$ e croma $\left(\mathrm{c}^{*}\right)$ em frutos de morangueiro, em análise conjunta dos experimentos de Atibaia e Piracicaba. Piracicaba, ESALQ, 1996.

\begin{tabular}{|c|c|c|c|c|c|c|c|c|}
\hline Cultivares & $\begin{array}{l}\text { Razão } \\
\text { Basel } \\
\text { altura }\end{array}$ & $\begin{array}{c}\text { Teor de } \\
\text { sólidos } \\
\text { solúveis } \\
\text { (graus Brix) }\end{array}$ & $\mathrm{pH}$ & textura & $\begin{array}{l}\text { Cor } \\
\text { interna } \\
\text { Luminosi- } \\
\text { dade }\left(L^{*}\right)\end{array}$ & $\begin{array}{l}\text { Cor } \\
\text { interna } \\
\text { Croma } \\
\left(c^{*}\right)\end{array}$ & $\begin{array}{l}\text { Cor } \\
\text { externa } \\
\text { Luminosi- } \\
\text { dade (L*) }\end{array}$ & $\begin{array}{c}\text { Cor } \\
\text { externa } \\
\text { Croma } \\
\left(c^{\star}\right)\end{array}$ \\
\hline Campinas & $0,942 a$ & $8,37 a$ & $3,77 \quad b$ & 85,75 & $43,66 \mathrm{a}$ & $39,17 \mathrm{ab}$ & $34,15 a$ & $34,29 a$ \\
\hline Dover & $0,652 \quad c$ & $7,10 \quad c$ & $3,66 \quad c$ & $123,27 b$ & 49,26 a & $32,47 \quad c$ & $30,10 \mathrm{~b}$ & $28,66 \mathrm{~b}$ \\
\hline Guarani & & $7,20 \quad c$ & 3,58 & 144,78 a & $35,81 \quad b$ & $43,68 \mathrm{a}$ & $28,27 \quad c$ & 21,23 \\
\hline $\begin{array}{l}\text { Princesa } \\
\text { Isabel }\end{array}$ & $0,838 \quad b$ & $7,77 \quad b$ & $3,84 a$ & $110,26 \mathrm{~b}$ & 48,77 a & 36,63 bc & $33,01 \mathrm{a}$ & 33,96 a \\
\hline AGF 080 & $0,944 a$ & $8,52 \mathrm{a}$ & $3,77 \quad b$ & 82,75 & 47,33 a & $38,42 \quad b$ & 34,12 a & 34,43 a \\
\hline$\overline{\mathrm{CV} \%}$ & 1,920 & 4,532 & 1,051 & 23,59 & 14,70 & 12,60 & 8,42 & 18,29 \\
\hline
\end{tabular}

*/ Médias seguidas da mesma letra não diferem estatisticamente pelo teste de Tukey, $5 \%$.

frutos com "pescoço" e Princesa Isabel $41,7 \%$ dos frutos com "pescoço". Como as cultivares Campinas, AGF 080 e Princesa Isabel apresentaram menos de 95\% dos frutos com uma mesma característica, não foi possível definir a qual das duas categorias pertenciam (Figura 1). Os resultados obtidos com a cultivar Guarani demonstraram sua característica de produção de morangos para uso industrial pela facilidade na remoção do cálice, finalidade para a qual havia sido selecionada.

A forma do fruto do morangueiro é de fundamental importância para o sucesso das cultivares devido às exigências do mercado consumidor. Sendo, no entanto, uma característica de difícil identificação pela análise comparativa com formatos padrões estabelecidos de maneira diferente, por vários autores (Passos, 1982; Lemaitre \& Linden, 1968; Queiroz-Voltan et al., 1996). Diante da dúvida de qual dos sistemas propostos pelos autores acima mencionados utilizar e, aliado ao fato de que quatro das cinco cultivares estudadas apresentarem formato muito semelhante, tipo cônico ou cônico-alongado, decidiu-se propor um novo sistema para distinguir frutos com formato tipo cônico.

$\mathrm{Na}$ análise conjunta dos experimentos, as cultivares Campinas e AGF 080 não apresentaram diferenças significativas entre si mas diferiram da Dover e da Princesa Isabel. As cultivares Campinas e AGF 080 apresentaram a maior relação entre a base e a altura do fruto $(0,943)$, o que caracteriza um formato de fruto pouco alongado, assemelhan- do-se a um "pião". Com valores menores ficou a cultivar Princesa Isabel e com os valores mais baixos a cultivar Dover, o que significa frutos com o formato mais cônico alongado entre as quatro cultivares testadas (Tabela 1 e Figura 1).

O teor de sólidos solúveis é característica de interesse para frutos comercializados in natura pois o mercado consumidor prefere frutos doces. Os resultados obtidos com o teor de sólidos solúveis estimados em graus Brix (Tabela 1), evidenciaram, como esperado, grande variação nas cultivares testadas contudo não houve variação significativa para o fator locais. Na análise conjunta dos experimentos as cultivares Campinas e AGF 080 apresentaram os maiores valores de graus Brix, em seguida ficou a cultivar Princesa Isabel e diferente destes mas semelhantes entre si as cultivares Guarani e Dover.

Passos (1982) em experimento realizado em Jundiaí, 1979, chegou aos valores de 8,10 graus Brix para a cultivar Campinas e 5,20 para a cultivar Guarani em frutos "maduros". No presente trabalho, o teor de sólidos solúveis em Atibaia, onde o clima é semelhante a Jundiaí, foi de 8,45 graus Brix na cultivar Campinas e 7,10 graus Brix na cultivar Guarani. Podemos afirmar que o valor elevado no teor de sólidos solúveis da cultivar Campinas confirma a descrição de Camargo \& Passos (1993), que consideram esta cultivar de sabor adocicado e o sabor da cultivar Princesa Isabel, menos doce que a cultivar Campinas, como suave-adocicado.
$\mathrm{O} \mathrm{pH}$ dos frutos apresentou variação significativa entre as cultivares. A análise conjunta dos experimentos de Atibaia e Piracicaba apresentou valores de $\mathrm{pH}$ mais elevados para a cultivar Princesa Isabel. Em seguida, diferentes dos demais mas semelhantes entre si, ficaram as cultivares Campinas e AGF 080 seguidas por Dover e Guarani (Tabela 1). A determinação do $\mathrm{pH}$ dos frutos é importante na definição da finalidade de uso das cultivares. $\mathrm{O}$ pH ácido é propriedade de morangos para uso industrial (Passos, 1982), e o mercado consumidor para frutos in natura prefere frutos pouco ácidos. A característica de $\mathrm{pH}$ torna difícil o desenvolvimento de cultivares de dupla aptidão, já que as exigências para cultivares de uso industrial e consumo in natura são opostas.

Comparando com os resultados obtidos por Passos (1982) e no presente trabalho, em Atibaia, notamos que o $\mathrm{pH}$ médio dos frutos foram semelhantes para a cultivar Campinas e diferentes para a cultivar Guarani. O fruto de Guarani, considerado ácido por Camargo \& Passos (1993) também apresentou valores mais baixos de $\mathrm{pH}$ neste trabalho.

As diferenças de textura e cor são de fundamental importância para o produtor na escolha das cultivares, mas é difícil diferenciar as texturas muito firme da firme, e esta da pouco firme, e também as tonalidades da cor vermelha. A caracterização quantitativa de caracteres fornece parâmetros mais exatos quanto às propriedades de textura e cor dos frutos, 
Tabela 2. Produção total (g/planta), número total/planta e peso médio (g) de frutos de morangueiro em Atibaia e Piracicaba e análise conjunta dos experimentos. Piracicaba, ESALQ, 1996.

\begin{tabular}{|c|c|c|c|c|c|c|c|c|c|}
\hline \multirow{2}{*}{ Cultivares } & \multicolumn{3}{|c|}{$\begin{array}{l}\text { Produção total de frutos } \\
\text { (g/planta) }\end{array}$} & \multicolumn{3}{|c|}{ Número total de frutos/planta } & \multicolumn{3}{|c|}{ Peso médio de frutos $(\mathrm{g})$} \\
\hline & Atibaia & Piracicaba & $\begin{array}{l}\text { Atib.x } \\
\text { Pirac. }\end{array}$ & Atibaia & Piracicaba & $\begin{array}{l}\text { Atib.x } \\
\text { Pirac. }\end{array}$ & Atibaia & Piracicaba & $\begin{array}{l}\text { Atib.x } \\
\text { Pirac. }\end{array}$ \\
\hline Campinas & $494,02 \mathrm{a}$ & $321,35 a$ & $407,69 a$ & $49,78 \mathrm{a}$ & $38,48 \mathrm{a}$ & $44,13 \mathrm{a}$ & $9,91 \quad b$ & $8,33 b$ & $9,12 b$ \\
\hline Dover & 475,57 a & $306,34 a b$ & 390,96 a & $46,14 a b$ & 34,39 a & 40,26 a & $10,32 \mathrm{ab}$ & $8,90 \mathrm{a}$ & 9,61 a \\
\hline Guarani & 496,87 a & $263,09 a b$ & 379,98 a & 52,66 a & $36,11 \mathrm{a}$ & $44,38 \mathrm{a}$ & $9,41 \quad c$ & $7,28 \quad \mathrm{c}$ & $8,35 \quad c$ \\
\hline $\begin{array}{l}\text { Princesa } \\
\text { Isabel }\end{array}$ & 394,18 b & $236,63 b$ & $315,40 \mathrm{~b}$ & $37,03 \mathrm{~b}$ & $25,66 \mathrm{~b}$ & $31,34 \quad b$ & $10,64 a$ & $9,22 \mathrm{a}$ & $9,93 a$ \\
\hline AGF 080 & $480,90 \mathrm{a}$ & $311,62 \mathrm{a}$ & 396,26 a & 48,12 a & 38,11 a & $43,12 \mathrm{a}$ & $10,00 \mathrm{~b}$ & $8,12 b$ & $9,06 \quad b$ \\
\hline $\mathrm{CV} \%$ & 10,690 & 11,179 & 11,165 & 9,717 & 9,468 & 9,494 & 2,070 & 2,974 & 3,113 \\
\hline
\end{tabular}

*/ Médias seguidas da mesma letra não diferem estatisticamente pelo teste de Tukey, $5 \%$.

e também contribui para definir a finalidade de uso das cultivares.

Os dados de resistência à compressão expressos em gramas permitiram classificar a textura dos frutos, considerando a média geral das cultivares $(109,36 \mathrm{~g})$ mais ou menos o desvio padrão $(25,80)$ para expressar os limites para frutos de textura firme. Frutos com resistência à compressão acima do limite desta amplitude, ou seja 135,16 g, foram considerados muito firmes e aqueles com valores abaixo deste limite, ou seja $83,55 \mathrm{~g}$, foram considerado pouco firmes. Esta classificação, mesmo baseada em poucas cultivares, parece representativa da situação real já que os frutos das cultivares estudadas têm ampla variabilidade quanto à textura pois pela descrição de Passos \& Camargo (1993) a cultivar Guarani tem frutos muito firmes, Princesa Isabel tem frutos regularmente firmes e Campinas frutos firmes.

Verificou-se que não houve diferença significativa quanto à textura dos frutos entre locais. Contudo, verificou-se que as cultivares, de fato, apresentaram valores de resistência à compressão diferentes, permitindo classificar a cultivar Guarani como de grande resistência à compressão ou textura muito firme, com o valor médio de 144,78 g. As cultivares Dover e Princesa Isabel, respectivamente com 123,27 g e 110,26 g, não apresentaram diferenças estatisticamente significativas entre si, podendo ser considerados frutos de textura firme, enquanto que as cultivares Campinas e AGF 080 com os valores de $85,75 \mathrm{~g}$ e
$82,75 \mathrm{~g}$, respectivamente, e não diferentes entre si, ficaram situadas no limite entre as de textura firme e pouco firme (Tabela 1).

Com estes dados, os valores de textura das cultivares Campinas e AGF 080 indicam que os frutos destas, têm a característica que o consumidor de frutos in natura aprecia, contudo pode ser limitante para o transporte de frutos, pois estes podem sofrer danos mecânicos com facilidade. Os frutos firmes da cultivar Princesa Isabel apresentaram textura que permite o comércio em mercados mais distantes, diminuindo a perda de frutos, pois estes, também podem suportar mais tempo depois de colhidos. Paraskevopoulou-Paroussi et al. (1995) demonstraram que frutos mais firmes mantém melhor a qualidade durante o período de armazenamento. A cultivar Dover, apesar da aparente firmeza de seus frutos, apresentou valores menores que a cultivar Guarani, possivelmente devido à maior firmeza da polpa interna da cultivar Dover.

Passos (1982), em experimento realizado em Jundiaí (SP), estimou a textura através da resistência à ruptura nas cultivares Campinas e Guarani, e verificou que em frutos maduros a textura da cultivar Campinas foi de 42,25 lbf/ $50 \mathrm{~g}$ e na cultivar Guarani de $62,50 \mathrm{lbf} /$ $50 \mathrm{~g}$. Estes resultados guardam relação com a textura do fruto, determinada no presente trabalho, que indicou maior firmeza dos frutos da cultivar Guarani em relação a Campinas.

Os dados de cor dos frutos do morango inteiro ou a cor externa e os com- ponentes $\mathrm{L}^{*}$ e $\mathrm{c}^{*}$, não mostraram diferenças significativas entre locais. As cultivares Campinas, AGF 080 e Princesa Isabel não diferiram entre si e a cultivar Princesa Isabel apresentou valores inferiores de luminosidade e croma em relação às demais. Dover e Guarani diferiram significativamente entre si e das demais cultivares, apresentando ainda, Guarani, os menores valores de L* e c* em relação às demais (Tabela 1). Apesar das diferenças significativas encontradas entre as cultivares, pela classificação proposta, as cultivares Campinas, AGF 080, Princesa Isabel e Dover foram consideradas de coloração e luminosidade intermediárias e somente Guarani se destacou por apresentar valores de $\mathrm{c}^{*}$ inferiores a 24,92 e de L* inferiores a 29,24 caracterizando coloração externa escura e mais cromática, o que concorda com as avaliações visuais (Figura 1).

Para as cinco cultivares a cor interna dos morangos, expressos pelos componentes $\mathrm{L}^{*}$ e $\mathrm{c}^{*}$, não variou entre os experimentos. Quanto à luminosidade, as cultivares Dover, Princesa Isabel, AGF 080 e Campinas não diferiram significativamente entre si, tendo diferido da Guarani que apresentou valor de L* de 35,81. Pela classificação proposta, estas cultivares ficaram no grupo intermediário e Guarani no grupo de coloração escura. Quanto ao croma dos frutos, as cultivares mostraram diferenças, sendo Campinas, AGF 080 e Princesa Isabel do grupo intermediário, a cultivar Dover foi considerado pouco cromático e Guarani muito cromático (Ta- 


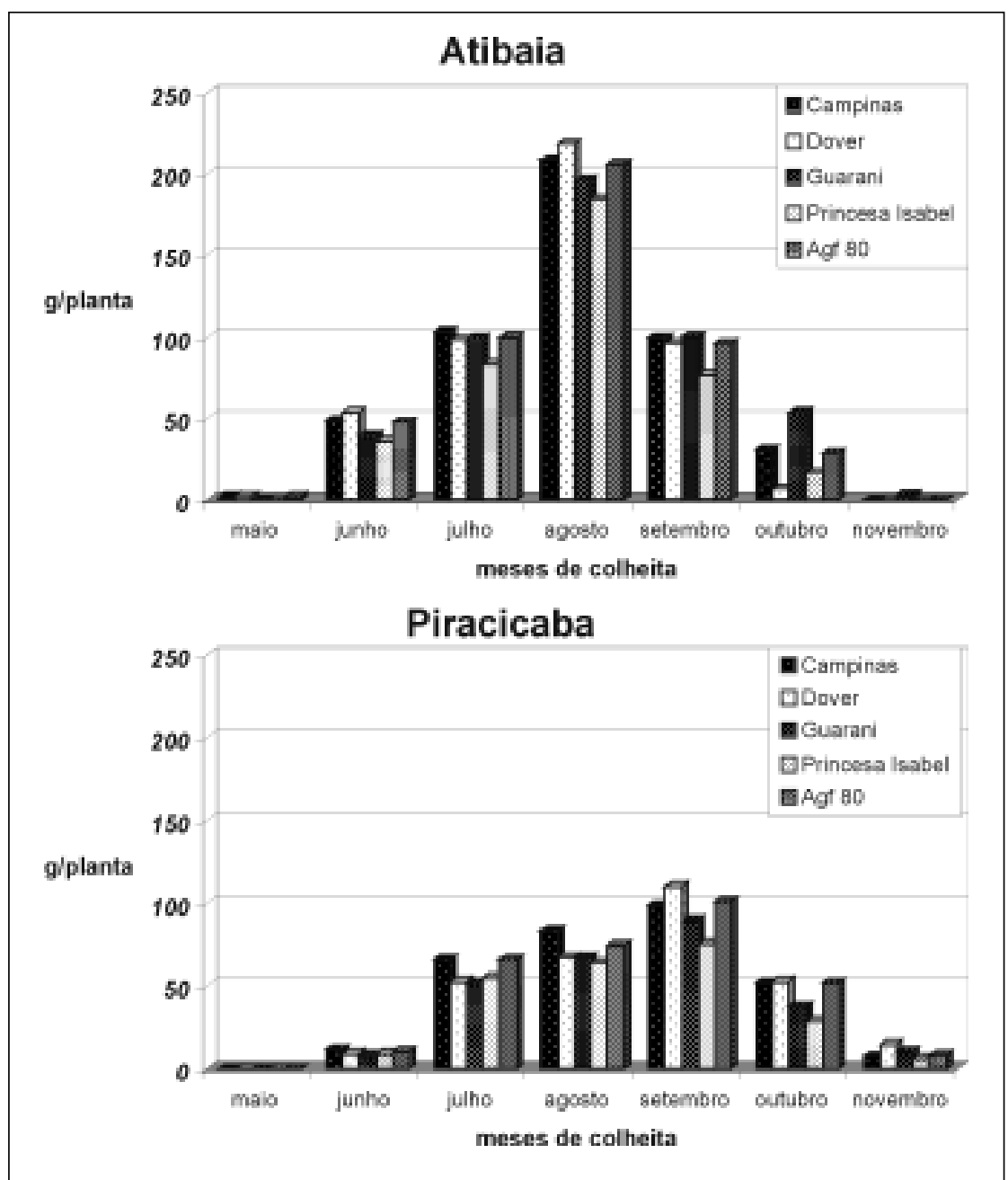

Figura 2. Produção mensal de frutos de morangueiro (g/planta), de cinco cultivares, em Atibaia e Piracicaba. Piracicaba, ESALQ, 1996.

bela 1). A coloração interna é uma das mais importantes características do morango para uso industrial. O vermelho intenso da cultivar Guarani quando observada visualmente, também refletiu em um valor de croma maior que 42,88 e em um valor de $L^{*}$ menor que 38,35 . Os dados mostraram que Dover não tem coloração interna vermelho intensa, pois tem valor de $\mathrm{L}^{*}$ de 49,26 e de croma de 32,47 , o que deve prejudicar o seu uso na industrialização.

Passos (1982) estudou os componentes $\mathrm{L}^{*}, \mathrm{a}^{*} \mathrm{e} \mathrm{b}^{*}$ utilizando método mais simples que o deste trabalho, e também fez a análise subjetiva de cor e verificou que a cultivar Guarani apresentou, para coloração interna, valores elevados de a* e baixos de L*, caracterizando vermelho intenso, coincidindo com as avaliações subjetivas. Os resultados deste e AGF 080 apresentaram as maiores produções totais de frutos (respectivamente 321,35 e 311,62 g/planta), seguidas de Dover e Guarani com valores de produção respectivamente de 306,34 e $263,09 \mathrm{~g} /$ planta mas as diferenças obtidas entre estas quatro cultivares não foram significativas. A cultivar Princesa Isabel apresentou a menor produção (236,63 g/planta), diferindo significativamente de 'Campinas' e 'AGF 080' mas não diferindo significativamente de 'Guarani' e 'Dover' (Tabela 2).

Os resultados deste trabalho mostraram que a cultivar Dover atinge níveis de produção elevados, semelhantes às cultivares Campinas, AGF 080 e Guarani que apresentaram produção alta já comprovada em condições experimentais e em áreas de produção. Os resultados da análise conjunta destacaram a cultivar Princesa Isabel com a menor produção $(315,40 \mathrm{~g} /$ planta $)$ e significativamente diferente das demais (Tabela 2).

A produção total de frutos neste trabalho, em Atibaia, pode ser comparada com outros experimentos com morango sob condições de manejo e clima semelhantes. Passos (1982) obteve em Jundiaí (SP), respectivamente nos anos de 1979 e $1980,434,18$ e 424,37 g/planta com a cultivar Campinas e 524,97 e $529,75 \mathrm{~g} /$ planta com a cultivar Guarani. Tessarioli Neto (1982), em São Bento do Sapucaí (SP) no ano de 1979, obteve produções de $387,08 \mathrm{~g} /$ planta com a cultivar Campinas e 520,67 g/planta com Guarani. Tessarioli Neto (1993), testou diversos tipos de cobertura de solo em morangueiro na cultivar Campinas em Monte Alegre do Sul (SP) e atingiu a produção de 494,74 g/planta com a cobertura de plástico de polietileno preto aplicado 21 dias após o transplante das mudas. Os resultados obtidos por estes autores foram concordantes com os deste trabalho. Passos (1997), em Atibaia, com a cultivar Campinas, testou diversos sistemas de produção e na área com irrigação por aspersão e cobertura de solo com plástico de polietileno preto, obteve produções de $171 \mathrm{~g} /$ planta em 1994 e $277 \mathrm{~g} /$ planta em 1995. No entanto, o autor comenta que no ano de 1994 houve ocorrência de geada prejudicando a produção precoce, e em 1995 o plantio ocorreu no 
dia 9 de junho, tardio para a região, o que pode ter prejudicado a produção total de frutos.

Analisando a produção pelo peso de frutos produzidos mensalmente, para todas as cultivares, notamos que em Atibaia e em Piracicaba o pico na colheita deu-se nos meses de agosto e setembro, respectivamente (Figura 2). Sendo, ainda, a produção média das cinco cultivares em Atibaia (468,30 g/planta) significativamente maior que em Piracicaba $(287,81 \mathrm{~g} /$ planta). Os resultados obtidos concordam com Tessarioli Neto (1993) que obteve, na cultivar Campinas, o pico de produção no mês de setembro com 123,28 g/planta.

A produção precoce de frutos, ou seja, aqueles produzidos nos meses de abril, maio e junho é a mais valorizada no Brasil e por esta razão, segundo Passos (1982), esta característica é muito importante para a seleção de cultivares nos trabalhos de melhoramento. De acordo com os resultados obtidos (Figura 2), as cultivares analisadas foram semelhantes quanto à produção precoce nos meses de maio, junho e julho, o que já era esperado pois as cultivares Campinas, Guarani e Princesa Isabel, foram selecionadas pelo IAC para possuírem esta característica. A cultivar Dover mostrou semelhança àqueles selecionados pelo IAC, podendo ter sido a produção precoce um dos motivos que o tornou de grande aceitação pelo produtor de morangos.

A cultivar Princesa Isabel foi aquela que apresentou o menor número de frutos produzidos com valores significativamente inferiores das demais na análise conjunta e na análise isolada do experimento de Piracicaba. Em Atibaia, o número de frutos produzidos pelas cultivares Dover e Princesa Isabel não diferiu estatisticamente, produzindo a menor quantidade de frutos e diferindo significativamente de Campinas, AGF 080 e Guarani (Tabela 2).

Os resultados obtidos com as cultivares Campinas e Guarani foram inferiores, porém muito próximos àqueles citados por Tessarioli Neto (1993): 56,52 frutos/planta para a cultivar Campinas e Tessarioli Neto (1982): 72,32 frutos/planta para Guarani, mas superiores para a cultivar Campinas, aos obtidos por Tessarioli Neto (1982): 48,96 e por
Passos (1997): 23,22 frutos por planta.

O peso do fruto é uma das características de maior importância agronômica na produção comercial do morango pois está diretamente relacionado ao tamanho do mesmo. Hortynski et al. (1991) obtiveram uma correlação de $86,4 \%$ entre tamanho e peso de frutos. Frutos grandes tornam o processo de colheita e embalamento mais rápido além da sua valorização pelo mercado consumidor resultando em maiores ganhos ao produtor.

Os resultados da análise conjunta e do experimento de Piracicaba destacaram as cultivares Princesa Isabel e Dover com o maior peso médio dos frutos. Em seguida, Campinas e AGF 080 apresentaram peso médio dos frutos e a seguir a cultivar Guarani com o menor peso médio dos frutos. No experimento de Atibaia houve diferença em relação à cultivar Dover que apresentou peso médio dos frutos semelhante também às cultivares Campinas e AGF 080 (Tabela 2).

Resultados semelhantes aos aqui encontrados foram obtidos por outros autores sob condições de manejo e clima parecidos. O peso médio dos frutos no trabalho de Passos (1982) variou entre $9,34 \mathrm{~g}$ e $10,90 \mathrm{~g}$ para a cultivar Campinas e entre $7,50 \mathrm{~g}$ e $8,80 \mathrm{~g}$ para Guarani, em experimento conduzido em Jundiaí em 1979 pelo mesmo autor, respectivamente para frutos " $3 / 4$ maduros" e "maduros". Tessarioli Neto (1993) chegou ao valor de 8,81 g para a cultivar Campinas e Tessarioli Neto (1982) obteve o valor de $9,05 \mathrm{~g}$ para esta cultivar e 7,80 g para Guarani. Passos (1997) em experimento realizado em $1994 \mathrm{em}$ Atibaia com a cultivar Campinas atingiu o valor de 6,12 g. Estes resultados caracterizaram Dover e Princesa Isabel como cultivares de frutos grandes, demonstrando que, assim como 'Campinas' e 'AGF 080' têm esta característica importante para o mercado de frutos in natura.

Os dados de presença de "pescoço", produção, peso, teor de sólidos solúveis, $\mathrm{pH}$, cor interna expressa pelos componentes $L^{*}$ e c* e textura, expressa pela força de resistência à compressão de morangos, deram parâmetros importantes para determinar em cada cultivar, isoladamente, a aptidão aos consumos in natura e industrial e também para analisar o desempenho produtivo e aspectos ligados à comercialização. As cultivares Campinas e AGF 080, pelas características do fruto de textura firme a pouco firme, elevado teor de sólidos solúveis e tamanho grande, expresso pelo peso elevado, caracterizaram aptidão ao consumo "in natura". Estas cultivares também apresentaram elevado desempenho produtivo, no entanto, pela textura dos frutos não são adequadas ao transporte a longas distâncias. A cultivar Guarani, pelas características do fruto de presença de pescoço, $\mathrm{pH}$ ácido, textura muito firme e cor interna vermelho intensa, demonstraram ter aptidão ao uso industrial. A textura muito firme de seus frutos também a tornam adequada ao transporte a longas distâncias. Esta cultivar também apresentou elevado desempenho produtivo. A cultivar Dover apresentou elevada produção de frutos. Tem, também, frutos grandes, interessantes para o consumo in natura. No entanto, as características de pH ácido e teor baixo de sólidos solúveis o tornam inadequado ao consumo in natura. Para uso industrial, esta cultivar apresenta características de interesse como frutos com $\mathrm{pH}$ ácido e textura firme, no entanto os frutos não têm "pescoço" e a cor interna não é vermelho intensa o que o torna pouco apropriado ao uso industrial. Graças às características de textura firme esta cultivar é adequada para o transporte a longas distâncias. A cultivar Princesa Isabel, pelas características de peso elevado de frutos e $\mathrm{pH}$ pouco ácido, demonstrou aptidão ao consumo in natura. A textura elevada de seus frutos é maior que a das cultivares Campinas e AGF 080 o que não prejudica a aceitação pelo consumidor e, por outro lado, é mais resistente ao transporte.

\section{AGRADECIMENTOS}

O presente trabalho foi realizado graças ao apoio da FAPESP, processo 96/1606-2, do CNPQ, dos Departamentos de Horticultura e Genética da ESALQ/USP, das pesquisadoras Sonia Dedeca S. Campos e Vera L. P. Ferreira, do laboratório FEPISA do ITAL e do produtor rural Claudemir Rodrigues Spinassi de Atibaia (SP). 


\section{LITERATURA CITADA}

CAMARGO, L.S. Novas variedades de morangueiro no Estado de São Paulo. Piracicaba: ESALQ, USP, 1960. 48 p. (Tese doutorado). CAMARGO, L.S; ALVES, S.; SCARANARI, H.J.; ABRAMIDES, E. Novas cultivares de morangueiro para a região do "alto piracicaba" no planalto paulista. Bragantia, Campinas, v. $27, \mathrm{n}$. 10, p. 117-133, 1968.

CAMARGO, L.S; PASSOS, F.A. Morango. In: FURLANI, A.M.C.; VIEGAS, G.P. (Ed.) $O$ melhoramento de plantas no Instituto Agronômico. v. 1. Campinas: Instituto Agronômico. 1993. p. 411-432.

CRUZ, C.D.; REGAZZI, A.J. Modelos biométricos aplicados ao melhoramento genético. Viçosa: Imprensa universitária. 1994. 390 p. DÁVALOS, I.P.A. Una solucion a largo prazo en problemas de la fresa, mejoramiento genetico, zamora e irapuato, zonas vanguardistas de Mexico. PanAgfa, v. 65, n. 7, p. 31-33, 1979.

FERREIRA, V.L.P. Princípios e aplicações da colorimetria em alimentos. Campinas: ITAL, 1981, Instruções Técnicas, 19. 85 p.

HORTYNSKI, J.A.; ZEBROWSKA, J.; GAWRONSKI, J.; HULEWICZ, T. Factors influencing fruit size in the strawberry (Fragaria $x$ ananassa Duch.). Euphytica, v. 56, n.1, p. 6774, 1991.

HOWARD, C.M.; ALBREGTS, E.E. Dover Strawberry. HortScience, v. 15, n .4, p. 540, 1980.
HUMAN, J.P.; EVANS, E.P. The strawberry production in South Africa. Acta Horticulturae, v. 265, n. 2, p. 757, 1989.

LEMAITRE, R.; LINDEN, R. Le frasier à gros fruits. Description et identification de variétes. Gembloux: J. Duculot, S.A., 1968. 234 p.

MISZCZAK, A.; FORNEY, C.F.; PRANGE, R.K. Development of aroma volatiles and color during postharvest ripening of 'Kent' strawberries. Journal of the American Society for Horticulture Science, v. 120, n. 4, p. 650-5, 1995.

NAGAI, V.; PASSOS, F.A.; SCARANARI, H.J.; MARTINS, F.P. Tamanho da parcela e número de repetições em experimentos com morangueiro. Bragantia, Campinas, v. 37, n. 9, p. 71-81, 1978. PARASKEVOPOLOU-PAROUSSI, G.; VASSILAKAKIS, M.; DOGRAS, C. Effects of temperature, duration of cold storage and packaging on postharvest quality of strawberry fruit. Acta Horticulturae, v. 379, p. 337-44, 1995. PASSOS, F.A. Caracterização de clones nacionais e introduzidos de morangueiro (Fragaria $\mathrm{x}$ ananassa Duch.), visando o uso imediato na horticultura e o melhoramento genético. Piracicaba: ESALQ, USP, 1982. 116 p. (Dissertação mestrado).

PASSOS, F.A. Influência de sistemas de cultivo na cultura do morango (Fragaria $\mathrm{x}$ ananassa Duch.) Piracicaba: ESALQ, USP, 1997. 105 p. (Tese doutorado).

PASSOS, F.A.; CAMARGO, L.S. Morango. In: FURLANI, A.M.C.; VIEGAS, G.P. O melhoramento de plantas no Instituto Agronômico. Campinas: Instituto Agronômico, 1993. p. 411-432.
PASSOS, F.A.; GRIDI-PAPP, I.L.; CAMARGO, C.E.O. CHIAVEGATO, E.J.; DALL'ORTO, F.A.C.; NAGAI, H.; GODOY, I.J. FAZUOLI, L.C.; VEIGA, R.FA. Descritores mínimos para o registro institucional de cultivares: MORANGO. Campinas: IAC, 1994. 8 p. (IAC Documentos, 40). QUEIROZ-VOLTAN, R.B.; JUNGMENDAÇOLLI, S.L.; PASSOS, F.A.; SANTOS, R.R. Caracterização botânica de cultivares de morangueiro. Bragantia, Campinas, v. 55, n. 1, p. 29-44, 1996.

RICE JR. R.P. Effects of cultivar and environmental interactions on runner production, fruit yield, and harvest timing of strawberry (Fragaria $x$ ananassa) in Zimbabwe. Acta Horticulturae, v. 279, p. 327-332, 1990.

SACKS, E.J.; SHAW, D.V. Color change in fresh strawberry fruit of seven genotypes stored at $0^{\circ}$ C. HortScience, v. 28, n. 3, p. 209-10, 1993.

SCOTT, D.H.; LAWRENCE, F.J. Strawberries. In: JANICK,J.; MOORE, N.M. Advances in fruit breeding. Indiana: Purdue University Press. 1975. p.71-92.

TESSARIOLI NETO, J. Avaliação do potencial produtivo e de seus componentes em diferentes clones de morangueiro (Fragaria $\mathrm{x}$ ananassa Duch.). Piracicaba: ESALQ, USP, 1982. 82 p. (Dissertação mestrado).

TESSARIOLI NETO, J. Influência de cobertura permeável e impermeável sobre o solo e planta na produção do morangueiro (Fragaria $\mathrm{x}$ ananassa Duch.). Piracicaba: ESALQ, USP, 1993. 112 p. (Tese doutorado) 